\title{
Postmortem Evaluation of Rabbit Carcasses Using Insect Populations in Keffi Nasarawa State, Nigeria
}

\author{
H. O. Akpa, J. D. C. Tongjura, G. A. Amuga, and R. J. Ombugadu
}

\section{ABSTRACT}

Untimely, forceful, and unexpected death is inevitable and common worldwide. Evidence for causes of death may be obtained through the knowledge of insects' successional pattern and postmortem interval on dead carcasses. Two rabbits (Lepus cuniculus) weighing $2.5 \mathrm{~kg}$ each were used as the experimental animals. The rabbits were sacrificed by poisoning and stabbing, postmortem evaluation was achieved by taking record of the insect's successional pattern. The insects' successional pattern revealed the following insects' species in order in which they arrived on the carcasses: Musca domestica, Lucilia sericata, Chrysomya albiceps, Dermestes maculatus, and Armadillidium vulgare (usual sp). The family Formicidae were represented by two unidentified species. $M$. domestica arrived first on the stabbed carcass while $L$. sericata on poisoned carcass. A total of $105 \pm 50$ insects were collected throughout the study period, with stabbed rabbit contributing $61 \pm 10$ and poisoned $44 \pm 60$ insects' species. Variation in the number of forensically important insects' species encountered in the study site did not show any significant difference $(p>0.05)$ in relation to each decomposition stage. There was however a significant difference $(p<0.05)$ between insects' relative abundance and mode of killing. Insect evidence was found 3 minutes after death on the stabbed carcass and 3 days after on the poisoned carcass. The study has shown that insects' population can be used to establish postmortem evidence in rabbit carcasses.

Keywords: carcass, insects, poison, postmortem, succession, stab.
Published Online: November 19, 2021

ISSN: 2684-5199

DOI : $10.24018 /$ ejbio.2021.2.6.247

\section{H. O. Akpa *}

Department of Zoology, Faculty of Natural and Applies Sciences, Nasarawa State University, Keffi, Nigeria.

(e-mail: hajarayusufo@gmail.com)

J. D. C. Tongjura

Department of Zoology, Faculty of Natural and Applies Sciences, Nasarawa State University, Keffi, Nigeria.

(e-mail: jctonjura@gmail.com)

G. A. Amuga

Department of Zoology, Faculty of Natural and Applies Sciences, Nasarawa State University, Keffi, Nigeria.

(e-mail: kamuga2@yahoo.com)

R. J. Ombugadu

Department of Zoology, Faculty of Natural and Applies Sciences, Nasarawa State University, Keffi, Nigeria.

(e-mail: ruthombugadu@gmail.com)

*Corresponding Author

\section{INTRODUCTION}

Forensic entomology is the scientific study of the invasion of the succession pattern of arthropods with their developmental stages of different species found on decomposed cadavers during legal investigations [1]. Insects are attracted to the decomposing body and may lay eggs in them. By studying the insect population and the developing larval stages, forensic scientists can estimate postmortem index, any change in position of the corpse as well as the cause of death [2]. Decomposing remains present a transient habitat and food resource opportunity for numerous insect species [3]. Within hours of death, insect groups such as blowflies (Diptera: Calliphoridae) are attracted to decomposing remains which are both a source of protein for egg development and a site for oviposition [4]. Insects are attracted to specific states of decomposition (e.g., bloated decay, fermentation, mummification, or skeletonization). Most species colonize a corpse for only a limited period of time. This change of insects over time is called faunal succession [5]. The colonization time, development time and departure time of the different insect species inhabiting remains are closely linked to the progression of carcass decomposition. As such, the age of the oldest immature insect specimen collected from remains, the next expected arrival of adult females, provides an indication of the minimum time that the decomposing remains were available for insect colonization and thus minimum postmortem interval (min PMI) [6]. The first organisms to arrive on a body after death are usually insects [7]. They arrive at a predictable time during the decomposition process. Each decomposition stage is attractive to a different group of Sarcophagus arthropods [7]. Data collected by Forensic Entomologists on arthropod populations, associated with carcass can be used to determine the place where the death occurred and whether or not there was ante mortem ingestion of toxins or drugs and to identify wound sites. However, the most valuable use of entomological data is the estimation of the postmortem interval (PMI) or the time that elapsed since death [8]. This study used insect populations to establish evidence on cause and time of death of rabbit carcasses.

\section{MATERIALS AND METHODS}

\section{A. Study Area}

The study was conducted in Keffi Nasarawa State Nigeria. Keffi is located between longitude $70.49^{\prime} 30^{\prime \prime}$ and latitude $80.807^{\prime} 35^{\prime \prime}$ and stands at an elevation of 400 meters above sea 
level. It is undergoing rapid population growth and infrastructural development due to its proximity to the Federal Capital of Nigeria. Keffi has an estimated population density of 450-500 people according to the 2006 census by the Nigerian populations' commission. Keffi has two distinct seasons, the wet season that begins around March and runs through October, and the dry season which begins from October and ends in March. The temperature ranges between 23-330C while the humidity ranges between $64-96 \%$. The annual rainfall is $602 \mathrm{~mm}$, while the monthly rainfall distribution intensifies during July, August, and September [9].

\section{B. Experimental Design}

Two rabbits (Lepus cuniculus) of average weight $2.5 \mathrm{~kg}$ were used as the experimental animals for this study as recommended [10]. They were obtained and kept in a metal cage to protect them from escape. They were also observed for one day for acclimatization and were feed with grasses and water.

The rabbits were taken alive to the study site and sacrifices separately at the selected sites within 2 hours intervals to enable close observation. The first rabbit was sacrificed by poisoning (with $5 \mathrm{~g}$ of organophosphate). [11]. The second rabbit was sacrificed by stabbing i.e., a sharp blow on the head with a metal rod, [10]. The rabbit sacrificed with poison was placed on the ground in the farm and the one sacrificed by stabbing was placed $70 \mathrm{~m}$ away from the previous one to avoid the same insects moving from one cage to the other. The carcasses were placed in rectangular wire cages staked to the ground to prevent the carcasses from being disturbed by scavengers but to allow access to both crawling and flying insects.

The ambient temperature (environmental) of the habitat was measured on daily basis using max/min thermometer throughout the period. The average temperature was used to determine the daily temperature.

\section{Collection, Preservation, and Identification of Insect Species}

Adult and developmental stages of insects were collected from different areas of the body and the soil. Insects' pitfall trap containing a saturated $\mathrm{NaCl}$ solution was placed around the carcass to trap crawling insects. Larvae were sampled with forceps while adults of flying insects were collected with a sweeping hand net.

The collected insects' species were anesthetized with diethyl ether and preserved in $70 \%$ ethanol. Insect identification was done using dichotomous keys. Adult flies were observed under a dissecting microscope and identified [11].

\section{Determination of Postmortem Interval}

Two approaches were used for determining postmortem interval: The first was by taking daily record of growth of the developmental stages of the insects and the second was insects' successional colonization. The postmortem interval was determined by taking a daily record of the duration of development of life stages (i.e., egg, larva, pupa, and adult) of forensic insect species on carcass till the first empty pupa case is noticed which indicate the emergence of the first insect generation.

\section{RESULTS AND DISCUSSION}

\section{A. Results}

\section{1) Species of Insects Collected Daily during the Time of} Decomposition for Poisoned Rabbit Carcass

Table I shows the species of insects collected daily during the time of decomposition for poisoned rabbit carcass. Five species of insects. (L. sericata, M. domestica, C. albiceps, A. vulgare, $D$. maculates with an unidentified sp. belonging to formicidea) were collected on the carcasses throughout the 23 days the study lasted. The initial numbers of colonizing insects decreased on the fifth day for the poisoned carcass. (Table I). There were no insects' activities at a fresh stage, but activities increased dramatically at the bloated stage then decreased at active decay, advanced decay, and dry stage respectively. Members of the family calliphoridae were the first to visit the poisoned carcass while the calliphoridae, and mucidae were noticed at bloated and active decay stage. Members of the family Dermestidae were only present at the advanced decay, while the formicidae were present throughout the last 3 stages. Armadilidiidae was noticed at advanced decay and dry stage of decomposition. The average temperatures recorded throughout the study were $24.5^{\circ} \mathrm{C}$ for fresh, $24{ }^{\circ} \mathrm{C}$ for bloated, $23.5{ }^{\circ} \mathrm{C}$ for active, advanced dry stages respectively. There were no significant differences $(\mathrm{P}>0.05)$ in the fresh and bloated decomposition stages of the recorded insect species. However, data analysis showed significant difference $(\mathrm{P}<0.05)$ in the insects' species recorded for active, advance and Dry decay stage of the rabbit.

TABLE I: MEAN VARIATION OF INSECT SPECIES IN RELATION TO DECOMPOSITION STAGES OF RABBITS SACRIFICED BY POISON: NS MEANS NOT SIGNIFICANT AND S MEANS SIGNIFICANT

\begin{tabular}{cccccc}
\hline Species & fresh & Bloated & $\begin{array}{c}\text { Active } \\
\text { decay }\end{array}$ & $\begin{array}{c}\text { Advance } \\
\text { decay }\end{array}$ & Dry \\
\hline L. sericata & $00 \pm 00$ & $2 \pm 10$ & $2.5 \pm 0.5$ & $00 \pm 00$ & $00 \pm 00$ \\
M. domestica & $00 \pm 00$ & $7 \pm 10$ & $4 \pm 10$ & $00 \pm 00$ & $00 \pm 00$ \\
D. maculates & $00 \pm 00$ & $00 \pm 00$ & $00 \pm 00$ & $0.5 \pm 00$ & $00 \pm 00$ \\
A. vulgare & $00 \pm 00$ & $00 \pm 00$ & $00 \pm 00$ & $3.5 \pm 0.5$ & $7 \pm 10$ \\
Unidentified & $00 \pm 00$ & $00 \pm 00$ & $3.5 \pm 0.5$ & $5.5 \pm 0.5$ & $8.5 \pm 0.5$ \\
p-values & 0.12 & 0.21 & 0.09 & 0.00 & 0.00 \\
$(0.05)$ & $\mathrm{NS}$ & $\mathrm{NS}$ & $\mathrm{NS}$ & $\mathrm{S}$ & $\mathrm{S}$ \\
\hline
\end{tabular}

\section{2) Species of Insects Collected Daily during the Time of} Decomposition for Stabbed Rabbit Carcass

Table II shows the species of insects collected daily during the time of decomposition for stabbed rabbit carcass. Six different species of insects were collected. (M. domestica, $C$. albiceps, L. sericata, A. vulgare D. maculates with an unidentified sp. belonging to formicidea). Throughout the 18 days the study lasted. The initial numbers of colonizing insects decreased on the third day for stabbed carcass (Table II). Members of the family Mucidae were the first to visit the stabbed carcass, with the mean $70 \pm 20$ for fresh and $40 \pm 00$ for bloated. They were present throughout the fresh and bloated stages of decomposition, while the Calliphoridae, was noticed at bloated and active decay stages. Members of the family Dermestidae were only present at the advanced decay stage. The Formicidae were present throughout the last 3 stages, (i.e., active decay, advanced decay and dry). The Armadilidiidae were noticed at the advanced decay stage of decomposition. The average temperatures throughout the 
study were $24.5^{\circ} \mathrm{C}$ for fresh, $24{ }^{\circ} \mathrm{C}$ for bloated, $23.5^{\circ} \mathrm{C}$ for active, advanced dry stage respectively. There were no significant differences $(\mathrm{P}>0.05)$ in the abundance of insect species recorded in fresh $(p=0.10)$ and bloated $(p=0.12)$ and active decay $(\mathrm{p}=0.15)$ decomposition stages of rabbits carcass sacrificed by stabbing. However, data analysis showed a significant difference $(\mathrm{P}<0.05)$ in the insects' species recorded for advanced decay and dry stages of Rabbit Carcass sacrificed by stabbing. Relative Abundance of Adult Insect in Relation to Mode of Sacrifice.

TABLE II: MEAN VARIATION OF INSECT SPECIES IN RELATION TO DECOMPOSITION STAGES OF RABBITS CARCASS SACRIFICED BY STABBING

\begin{tabular}{cccccc}
\hline Specie & Fresh & Bloated & $\begin{array}{c}\text { Active } \\
\text { Decay }\end{array}$ & $\begin{array}{c}\text { Advance } \\
\text { Decay }\end{array}$ & Dry \\
\hline $\begin{array}{c}\text { Musca } \\
\text { domestica }\end{array}$ & $70 \pm 20$ & $40 \pm 00$ & $00 \pm 00$ & $00 \pm 00$ & $00 \pm 00$ \\
$\begin{array}{c}\text { Chrysomya } \\
\text { albiceps }\end{array}$ & $4.5 \pm 0.5$ & $8.5 \pm 0.5$ & $00 \pm 00$ & $00 \pm 00$ & $00 \pm 00$ \\
$\begin{array}{c}\text { Lucilla sericata } \\
\text { Dermesties }\end{array}$ & $3.5 \pm 0.5$ & $6.5 \pm 1.5$ & $00 \pm 00$ & $00 \pm 00$ & $00 \pm 00$ \\
maculates & $00 \pm 00$ & $00 \pm 00$ & $0.5 \pm 00$ & $00 \pm 00$ & $00 \pm 00$ \\
Armadillidium & $00 \pm 00$ & $00 \pm 00$ & $00 \pm 00$ & $4 \pm 20$ & $00 \pm 00$ \\
vulgare & $00 \pm 00$ & $00 \pm 00$ & $3 \pm 10$ & $9 \pm 00$ & $9.5+0.5$ \\
Unidefied & 0.10 & 0.12 & 0.15 & 0.04 & 0.00 \\
P values $(0.05)$ & $\mathrm{NS}$ & $\mathrm{NS}$ & $\mathrm{NS}$ & $\mathrm{S}$ & $\mathrm{S}$ \\
\hline
\end{tabular}

Table III shows that four Orders; Diptera, (L. sericata, $M$. domestica and $C$. albiceps), Coleoptera, (D. maculates), Hymenoptera (unidentified sp) and Isoptera (A. vulgare) for poisoned rabbit carcass while three orders; Diptera, $(L$. sericata, M. domestica and C. albiceps), Coleopteran (D. maculates) and Isopteran (A. vulgare) for stabbed rabbit carcass. The result indicated that family Musidea was more abundant with both mode of sacrifice, with the stabbed rabbit having $(0.26 \%)$ and poisoned with $(0.22 \%)$ followed by $C$. albiceps which was only found on the stabbed carcass with $(0.26 \%)$ while $L$. sericata were the third with the percentage of $(0.2 \%)$ for stabbed and $(0.15 \%)$ for a poisoned carcass. $A$. vulgare were the fourth, having the highest number on poisoned $(0.21 \%)$ then the stabbed $(0.01 \%)$. The family Formicidae was the least and last to visit, with a reasonable number on the poisoned carcass but absent on the stabbed carcass. They were significant at $\mathrm{p}=0.005$.

TABLE III: RELATIVE ABUNDANCE OF AdUlt InSECT TO MODE OF SACRIFICE

\begin{tabular}{ccc} 
& \multicolumn{3}{c}{ SACRIFICE } \\
\hline Species (Order) & $\begin{array}{c}\text { No (\%) by mode of } \\
\text { sacrifice Poison }\end{array}$ & Stab \\
\hline $\begin{array}{c}\text { L. sericata (diptera: } \\
\text { Calliphoridae) } \\
\text { M. domestica (diptera: } \\
\text { Muscidae) }\end{array}$ & $15(17.04)$ & $20(16.39)$ \\
$\begin{array}{c}\text { C. albiceps (diptera: } \\
\text { Calliphoridae) }\end{array}$ & $22(25.00)$ & $26(21.31)$ \\
$\begin{array}{c}\text { D. Maculates (Coleoptera: } \\
\text { Dermestidae) }\end{array}$ & $2(2.27)$ & $1(0.81)$ \\
$\begin{array}{c}\text { Armadillidium vulgare } \\
\text { (Isoptera: Armadilidiidae) }\end{array}$ & $21(28.86)$ & $8(6.57)$ \\
$\begin{array}{c}\text { Unidentified (Hymenoptera: } \\
\text { Formicidae) } \\
\text { Total }\end{array}$ & $28(31.81)$ & $38(31.14)$ \\
\end{tabular}

\section{B. Discussion}

The use of animal model Carcass and forensic insects use of rabbit carcass in assessing insect fauna associated with poisoning and stabbing.

In this study, the stabbed rabbit carcass decayed faster than the poisoned carcass. Also, the insect fauna associated with the carcass colonized the stabbed carcass faster than the poisoned carcass. This observation could be attributed to the presence of toxic chemicals in the body of the poison rabbit carcass [14]. According to [15]. The presence of drugs and/or poison in a decomposing body may affect and decrease the rate of insect invasion of that body and subsequently affect the immature development but not the colonizing species. In organophosphate, did not override the odour of the decomposing carcass which attracted insect species. This is in line with the report of (4) who reported that application of carbon dioxide to poisoned carcass has no significant influence on the odour. In contrast [16], found that neither decomposition nor arthropod invasion occurred on rabbit carcass poisoned with arsenic oxide even after 11 months.

This study recorded decomposition stages including fresh stage, bloated stage, decay stage, post decay stage, and dry stage. Description of these stages was very similar to that described by Fazli and Syed [17]. Each stage was found to be colonized by specific insects' groups. In this study, a total of 5 insect species (for poisoned rabbit Carcass) and 6 species (for stabbed rabbit Carcass) were recorded throughout the decomposition period, which represent 5 families and four orders i.e., Diptera, Coleoptera, Isoptera and Hymenoptera related with Carrions [18]. These findings were parallel to the conclusion of Maramat and Rahim [19] who identified three major orders during their studies. Small size of Carcass samples could be a possible cause for the fewer number of insect species collected. This observation agrees with Mohammed [20] who reported the use of only three carcasses. The variation in the number of colonized species with respect to the poisoned and stabbed rabbit carcass could be attributed to the presence of the poisoned chemicals in the experimental rabbit carcass. Diptera, Coleoptera, Isoptera and hymenoptera dominate the carrion fauna, for both poisoned and stabbed rabbit carcass, during this investigation. This is in consistent with most of the previous studies, on carrion decomposition [11].

In this study, the insect successional colonization revealed the following insect species in order in which they arrived in the carcass; L. sericata, M. domestica, C. albiceps, D. maculates, and A. vulgare. M. domestica arrived first on the stabbed carcass while $L$. sericata arrived first on the poisoned carcass. Also, M. domestica was observed to be the most abundant insect species, followed by $L$. sericata irrespective of mode of killing. This observation is in agreement with associated with different types of animal bases carcasses have been well evaluated. [12]. Compared species composition of insects on the corpses of black bear, white-tailed deer, species alligator, and swine. Also, [13] evaluated the arthropod taxon richness on rat, rabbit, and long-tail monkey carcass. They provided differences in the number of species collected. The current study thus corroborates their findings and support the those of [11] and [21] who reported M. domestica providing the highest number of insect species on pig carcass in Southern and Norther Nigeria, respectively. Nyashamabika [10] observed M. domestica providing the highest number of flies from colonized carcass in Zimbabwe. On the contrary, [22] and Abdelbar and Sawaby [23] reported chrysomya 
species as the most abundance insect species colonizing rabbit carcass. This variation in findings could be as a result of different factors relating to the investigation including animal model, mode of killing, and other environmental factors.

The abundance of colonized insect fauna was higher in the stabbed rabbit carcass than in the poisoned rabbit carcass. This is in agreement with previous findings of Asraf and Meklafi [24], who observed disparity in the abundance of insect species colonizing the same animal carcass at different habitat in Egypt. This observation could be attributed to the fact that the organophosphate poison mask and/or override the decompositional odour, thereby repelling the insect species instead of attracting them to the carcass [11]. This implies that the mode of death must have induced several noticeable differences in the duration of development of the immature stages of Calliphoridae, Musidae, Dermestia, Armadiliddidae, and Fomidae. It can be inferred that the presence of chemical agent such as organophosphate poison in decomposing tissue, influences the development and pattern of carrion feeding insects and could alter post mortem interval estimates based on the rate of larval and puparial development [23]. Calliphorides and Musidae have been previously identified as the most important arthropods invader of carcass because of the influence they had on the rapid deterioration of the carcass [20].

\section{CONCLUSION}

In this study, it was observed that the pattern of insect occurrence and abundance in relation to the various decomposition stages recorded a very low abundance of Diptera at the fresh phase of decomposition, which increased gradually at the bloat stage and dramatically increased and reached its peak at the active decay stage.

However, the advanced decay stage witnessed a decline in the abundance of insect species (except for Isoptera and Hymenoptera) and disappearance of Calliphorid flies. Similar trend has been previously reported by [10], that active decay stage recorded the highest number of insects, and the fresh stage recorded the lowest in [11] in Niger State, Nigeria also reported similar observation in pig carcass. On the contrary, [12] showed that Caliphoridae continued their activity on pig carcass during the whole decomposition period.

\section{RECOMMENDATIONS}

1. There is need for government and concerned NGOs to integrate the use of insect fauna in crime detection in Nigeria.

2. There is need to establish the effect of other method of killing, seasonal variation and environmental factor on the insect succession and abundance in rabbit Carcass.

3. Further study to identify the residue of the poison in the colonized insect species is highly recommended.

\section{REFERENCES}

[1] M. M. Abd-El-bar, R. F. Sawaby. A preliminary investigation of insect colonization \& succession on remains of rabbits treated with own organophosphate insecticide in El-Qalyubiyal Governor rate of Egypt. Forensic Science International, vol. 208, pp. 26-30, 2011.

[2] J. Amendt, R. Zehner, R. Krettek. Forensic entomology. The Science of Nature, Vol. 91, Pp. 51-65, 2004.

[3] J. Amendt, C. P. Campobosso, E. Gaudry, C. Reiter, H. N. Le Blanc, M. J. R. Hall. Best practice in Forensic entomology, standards and guidelines. International Journal of Legal Medicine, vol. 121, pp. 90104, 2006.

[4] J. Amendt, C. P. Campobasso, E. Gaundry, C. Reiter, H. LeBlance, M Hall. Best Practice Forensic Entomology Standards and Guidelines. International Journal of Legal Medicine, vol. 121, pp. 90-104, 2007.

[5] J. Amendt, M. L. Goff, P. Carlo, C. M. Grassberger. Cuticular Hydrocarbons. A New Tool in Forensic Entomology. In Current Concepts in Forensic Entomology, (Eds F.P. Drijfhoutz,). Springer Dordrecht Heidelberg, New York, vol. 369, pp. 12-29, 2010.

[6] J. Amendt, C.P. Richards, R. Campobasso, C. S. Zehner, M.J. R. Hall. Forensic entomology applications and limitations. Journal of Forensic Science Medical Pathology, vol. 7, pp. 379-392, 2011.

[7] M. A. M. Ashraf, F. A. A. Meklafi. Differential Diptera Succession Different Habitats. Journal of Medical Entomology, vol. 2, pp. 1-6, 2016.

[8] A. Azwadi, K. H. Nina, L. C. Owen, M. D. Nurizzati, B. Omar. Adult carrion arthropod community in a tropical rainforest Malaysia. Tropical Biomedicine, vol. 30(3), pp. 481-494, 2013.

[9] M. Benecke. A brief history of forensic entomology. International Journal of Forensic Entomology, vol. 120(1), pp. 18-25, 2001.

[10] A. D. Chapman. Number of living species in Australia and the world. Journal of Australia biological resources study, vol. 5(3), pp. 232-237, 2006.

[11] A. Daniel. Forensic Pluralism and the Dead Body in Early 20thCentury China. Academic Forensic Pathology, vol. 11(1), pp. 41-51, 2021. 10.1177/19253621211002504

[12] F. Y. Dupont, B. B. Felix, C. Daniel, D. L. Champlain. Biodiversity study of the arthropods collected on rat carrion in Yaounde, Cameroon first study of forensic entomology in Central Africa. International Journal of Bioscience, vol. 2(1), pp. 1-8, 2012.

[13] E.M. EL-Kady, Y.E.E. Essa, O. Shalaby. Varitions in the Blow and flesh Flies Succession on Rabbit Carrions Killed by different Methods. Journal of Forensic Science, vol. 13, pp. 12-93, 1994.

[14] A. Fazli, F. S. Syed. Insect Succession on Rabbit (Oryctolagus cunicus L.) carrion in District Peshawar. International Journal of Bioscience, vol. 10(6), pp. 253-258, 2017.

[15] M. L. Goff, M. M. Flynn. Determination of postmortem interval by arthropode succession. Journal of forensic science, vol. 36(2), pp. 14 60, 1991.

[16] R. D. Hall. Perceptions \& status of forensic entomology. In Forensic Entomology the Utility of Arthropods in Legal Investigations, CRC Boca Raton, Florida, vol. 651, pp. 215-410, 2001.

[17] J. Isacc, G. Mathew, S. Pradeesh, V. Geetha. The use of insects in forensic investigations: An overview on the scope of forensic entomology. Journal of Forensic Dental Science, 130(1), pp. 89-91, 2011.

[18] A.I. Jibrin, I. K. Olayemi, A. T. Ande, F. O. Arimoro, M.O. Odeyemi, A. Ukubuiwe. Special Variation in Abundance of Forensically important Entomo-Fauna Inhabiting Decomposing Carcass in Minna, Nigeria. International Journal of Applied Biological Research, vol. 8(1), pp. 195-205, 2017.

[19] M. E. Lamia, H. Y. Mariam. Seasonality of Insect Succession on remains of rabbit treated with Amitriptyline (Antidepresant Drug) in Alexandria, Egypt. Journal of Advances in Biology, vol. 9(1), pp. 1-6, 2019.

[20] S. Matuszewski, K. Frateza, S. Konwerski. Effect of body mass and clothing on carrion entomofauna. International Journal of legal medicine, 130(1). pp. 1-12, 2015.

[21] R.R. Maramat, N. A. A. Rahim. A study of forensically important flies associated with decomposing rabbit carcasses in peat swamp forests in Kuching \& Kota Samarahan, Sarawak, East Malaysia. Journal of Biochemical biopharmaceutical \& biomedical sciences, vol. 1, pp. 3$11,2015$.

[22] G.M.Z. Mohammed, M.H. Kotb, A.F. Mohammed, A.A. Alaa, M.K Mohammed. Forensic-Insect Succession and Decomposition patterns of dog and rabbit Carcasses in different habitat. Journal of Entomology and Zoology Studies, vol. 3(5), pp. 473-482, 2015.

[23] M. Nyashamabika, M. Ron, M. Gilbert. An initial study of insect succession on decomposing Rabbit carrion in Harare Zimbabwe. Asian pacific Tropical Biomedical, vol. 4(7), pp. 561-565, 2014. 